\title{
El nuevo municipalismo: derecho a la ciudad y comunes urbanos
}

\section{The new municipalism: right to the city and urban commons}

\author{
Ismael Blanco \\ Universidad Autónoma de Barcelona \\ Ismael.Blanco@uab.cat
} NOTA BIOGRÁFICA

Profesor Agregado de Ciencia Política, Universidad Autónoma de Barcelona. Investigador en el Instituto de Gobierno y Políticas Públicas (IGOP-UAB). Investigador postdoctoral y profesor visitante en la De Monfort University (Leicester, Reino Unido) y en la Universidad Federal de Minas Gerais (Belo Horizonte, Brasil). Publicaciones más recientes: DAVIES, J. and BLANCO, I. (2017). "Austerity Urbanism: Patterns of Neoliberalisation and Resistance in Six Cities of Spain and the UK". Environment and Planning A. 44 (11): 2.687-2.704. CRUZ, H., MARTÍNEZ, R., BLANCO, I. (2017). "Crisis, urban segregation and social innovation in Catalonia". Partecipazione e Conflitto, 10 (1): 221-245. BLANCO, I. and LEÓN, M. (2016) "Social innovation, reciprocity and contentious politics: facing the socio-urban crisis in Ciutat Meridiana, Barcelona". Urban Studies, 54 (9): 2.172-2.188.

\section{NOTA BIOGRÁFICA}

Universidad Autónoma de Barcelona ricard.goma@uab.cat

Profesor Titular de Ciencia Política, Universidad Autónoma de Barcelona. Director del Instituto de Estudios Regionales y Metropolitanos de Barcelona. Máster en Políticas Públicas, University of Strathclyde (Glasgow, Reino Unido). Profesor visitante en las universidades de Warwick y Bath (Reino Unido). Publicaciones más recientes: BLANCO, I. GOMÀ, R. (2016). El municipalisme del bé comú. Barcelona: Icària. GOMÀ, R. ROSETTI, N. (2016). "Perfiles de exclusión y políticas de inclusión en España", Revista del CLAD Reforma y Democracia, núm. 64: 53-78. GOMÀ, R. SUBIRATS, J. (2017). Canvi d’època i polítiques públiques a Catalunya. Barcelona: Crític. BLANCO, I. GOMÀ, R. (2017). "Construyendo el municipalismo del bien común”, en OLMEDO, P. ENDARA, G. Alternativas urbanas y sujetos de transformación. Quito: Fundación F.Ebert.

Joan Subirats

Universidad Autónoma de Barcelona joan.subirats@uab.cat

\section{NOTA BIOGRÁFICA}

Catedrático de Ciencia Política, Universidad Autónoma de Barcelona. Investigador en el Instituto de Gobierno y Políticas Públicas (IGOP-UAB). Titular de la Cátedra Príncipe de Asturias en la Universidad de Georgetown (Washington, EEUU). Profesor visitante en la Universidad de Roma-La Sapienza, University of California-Berkeley, New York University, Universidad Nacional de México y Universidad de Buenos Aires. Publicaciones más recientes: RENDUELES, C. SUBIRATS, J. (2016). Los (bienes) Comunes. Barcelona: Icària. SUBIRATS, J. (2016). El poder de lo próximo. Madrid: La Catarata. PARÉS, M. OSPINA, S. SUBIRATS, J. Social innovation and democratic leadership. Londres: Edward Elgar. 


\title{
RESUMEN
}

El artículo ofrece en primer lugar una perspectiva general sobre la era urbana, entendida como un nuevo tiempo global donde las ciudades juegan un papel central, en tanto que espacios que producen y reflejan las grandes dinámicas vertebradoras de las primeras décadas del siglo XXI. Ello permite situar un segundo elemento de discusión: lo común y la proximidad como posibles respuestas donde generar proyectos colectivos de protección y reconocimiento. En ese sentido, el artículo plantea los retos clave de empoderamiento de las ciudades en redes horizontales de gobernanza. En un plano más concreto, la reflexión se traslada a la evolución del municipalismo en España: la trayectoria de tres décadas de gobiernos locales democráticos, las dinámicas recientes de movilización urbana, y el nuevo escenario surgido de las elecciones de 2015. A partir de ahí, el artículo plantea la posible configuración de un nuevo municipalismo definido por dos dimensiones: una agenda de políticas urbanas comprometidas con el derecho a la ciudad; y una agenda de prácticas urbanas vinculadas a la construcción del común. La Obra Social de la PAH se expone, finalmente, como caso que permite articular ambos aspectos: la producción de comunes urbanos y el ejercicio del derecho a la vivienda.

\section{PALABRAS CLAVE}

Global; ciudades; común; gobernanza; movimientos; vivienda.

\begin{abstract}
The article firstly draws an overall perspective on the urban age, a new global time where the cities play a central role as spaces which produce and reflect the key dynamics of the 21 st Century. On this grounds, a second set of ideas are brought together: the common and proximity as possible answers to create collective projects of protection and recognition. In this sense, the article discusses the main challenge of empowering cities within systems of network multilevel governance. More concretely, the development patterns of local government in Spain are considered: three decades of democratic local government, the recent emergence of new urban movements, and the scenario after the 2015 local election. At this point the article deals with the shaping of a new municipalist model defined by a twofold dimension: a policy agenda committed with the right to the city, and a set of urban practices oriented to common-building. Finally, the Obra Social de la PAH is considered as a case study which allows the analysis of both aspects: the production of urban commons and the access right to affordable housing.
\end{abstract}

\section{KEYWORDS}

Global; cities; commons; governance; movements; housing.

\section{SUMARIO}

INTRODUCCIÓN. 1. CAMBIO DE ÉPOCA Y LA NUEVA ERA URBANA: DE LA CIUDAD FORDISTA A LAS REDES DE METRÓPOLIS. 2. LO COMÚN Y LA PROXIMIDAD: CAPACIDADES COLECTIVAS FRENTE A JERARQUÍAS, CIUDADES FRENTE A ESTADOS?. 3. GOBIERNO LOCAL Y ACCIÓN COLECTIVA URBANA EN ESPAÑA: HACIA UN ESCENARIO DE NUEVO MUNICIPALISMO. 3.1. LA TRAYECTORIA DEL GOBIERNO LOCAL: TRES DÉCADAS DE CAMBIOS (1979-2011). 3.2. DINÁMICAS DE MOVILIZACIÓN URBANA (2011-2015). 3.3. EL ESCENARIO LOCAL POST-2015: HACIA UN NUEVO MUNICIPALISMO. 4. LA NUEVA AGENDA URBANA COMO CONSTRUCCIÓN DEL DERECHO A LA CIUDAD. Ecología urbana. Economías ciudadanas. Bienestar de proximidad. 5. LA NUEVA AGENDA URBANA COMO CONSTRUCCIÓN DEL COMÚN. 6. ARTICULAR DERECHO A LA CIUDAD Y COMUNES URBANOS. 6.1. LA PLATAFORMA DE AFECTADOS POR LA HIPOTECA: COPRODUCIR COMUNES URBANOS DE VIVIENDA. La Obra Social de la PAHC de Manresa: derecho a la vivienda, disidencia y producción del común. Apuntes finales: los retos del municipalismo del común. REFERENCIAS BIBLIOGRÁFICAS.

\section{INTRODUCCIÓN}

Este trabajo plantea dos cuestiones básicas. Por una parte, la articulación entre el cambio de época (entendido como proceso de cambio sociocultural con una fuerte dimensión urbana) y el binomio común/ 
proximidad (en tanto que posible esquema de respuesta al reto de forjar sociedades tanto abiertas como protegidas). Por otra parte, la articulación entre una agenda de políticas municipales orientadas al derecho a la ciudad, y formas de producción de esas políticas orientadas a la construcción de comunes urbanos. Así pues una primera cuestión que se desarrolla en un plano genérico de elaboración de marcos conceptuales, y una segunda que aporta reflexiones concretas sobre dinámicas y casos de estudio. Al efecto de tratar este conjunto de aspectos, el artículo se estructura en seis bloques. Los dos primeros situan el marco de referencia; el tercero revisa las pautas de evolución del municipalismo en España; el cuarto y el quinto plantean, en el contexto actual, el potencial de articulación de la nueva agenda urbana en sus dos dimensiones: la sustantiva como construcción del derecho a la ciudad, y la operativa como construcción del común. El último apartado aporta el caso de la obra social de la PAHC de Manresa como práctica que permite visualizar ambas dimeniones. El trabajo concluye apuntando posibles vías de avance en la investigación de las cuestiones tratadas.

\section{CAMBIO DE ÉPOCA Y LA NUEVA ERA URBANA: DE LA CIUDAD FORDISTA A LAS REDES DE METRÓPOLIS}

Cruzamos las primeras décadas del siglo XXI bajo una dinámica de cambio de época. Y sabemos que una de sus dimensiones clave se despliega a través de las ciudades. El tiempo nuevo que empezamos a vivir es un tiempo urbano, la era de las ciudades, como lo expresa la declaración final de Habitat III, la cumbre de Naciones Unidas sobre desarrollo urbano celebrada en Quito (2016). En efecto, si el tiempo de la sociedad industrial fue de la mano del espacio de los estados; el cambio de época viene vinculado al espacio de las ciudades.

El proceso sociocultural de cambio de época está llamado a dibujar las trayectorias personales y colectivas de las próximas décadas. Hacia finales del siglo xx los principales parámetros que habían vertebrado la primera modernidad se tambalean de forma irreversible. Va emergiendo un mundo de complejidad creciente en los contextos vitales; aparecen incertidumbres, discontinuidades biográficas y nuevas vulnerabilidades; irrumpe internet y sus espacios digitales de interacción; se redefinen referentes de identidad y anclajes comunitarios; emergen creatividades y energías ciudadanas de nuevo tipo (Beck, 1998; Bauman, 2003; Castells, 2012). La sociedad del riesgo, del conocimiento y líquida se abre paso con fuerza: nace una segunda modernidad, entre la reflexión y la posverdad; entre la individualización y el bien común.

Las cumbres de la ONU sobre las ciudades se celebran cada veinte años. La primera tuvo lugar en Vancouver en 1976, por entonces poco más del $30 \%$ de la humanidad vivía en asentamientos urbanos. Cuando la reunión de Estambul, en 1996, esa cifra alcanzaba ya el 40\%. En Quito se constata un indicador histórico: la mayoría de la población del planeta, un $54,5 \%$, es población urbana. Si la dinámica no se trunca, y nada lo hace prever, las ciudades pueden llegar a alojar al 70\% en 2050: de un tercio a dos tercios de la humanidad en menos de 100 años, una proceso demográfico impresionante. Pero no es sólo demografía, esas cifras reflejan mucho más: a) en las 500 ciudades más dinámicas del mundo vive el $23 \%$ de la población, pero se genera el $58 \%$ del PIB del planeta; b) la financiarización de la economía global tiene uno de sus anclajes principales en las rentas urbanas; c) las ciudades mayores de 300.000 habitantes son hoy responsables del $70 \%$ de todas las emisiones de gases de efecto invernadero; d) el índice de gini (distribución desigual del ingreso) ha crecido en las metrópolis un $20 \%$ en los últimos 20 años, con su correlato de segregación residencial.

En las ciudades se construye y se refleja el mundo del siglo XXI, con todas sus tensiones: dinamismo económico, especulación inmobiliaria, cambio climático, desigualdad. Es en este sentido que cobran hoy mucha fuerza los análisis que sitúan en lo urbano, en las grandes metrópolis del siglo XXI, los factores explicativos de los modelos socioeconómicos predominantes (Sassen, 2014; Harvey, 2016). También en las ciudades aparecen las lógicas de acción colectiva y las alternativas políticas más innovadoras e interesantes: el nuevo municipalismo como proyecto y praxis transformadora, de ampliación democrática, empoderamiento social y reconexión de las instituciones al bien común (Blanco y Gomà 2016). En síntesis se ha consolidado en las últimas décadas una realidad demográfica y territorial marcada por la hegemonía de lo urbano. Un predominio que se traslada a las esferas económica, social y ambiental, y situa a las metrópolis como verdaderos epicentros de la realidad cotidiana de la mayoría.

Las metrópolis de hoy son el resultado de interacciones complejas en el tiempo (Capel, 1975; Lefevbre, 2017). Es importante modelizar sus rasgos básicos para conocer las realidades sobre las cuales se deben 
GAPP. Nueva Época - N. 20, noviembre 2018 - ISSN: 1989-8991 - DOI: 10.24965/gapp.v0i20.10491 - [Págs. 14-28] Número monográfico - Gobernanza y políticas de desarrollo urbano: teoría y práctica

El nuevo municipalismo: derecho a la ciudad y comunes urbanos Ismael Blanco / Ricard Gomà / Joan Subirats

desplegar políticas públicas y dinámicas de gobernanza. Podemos partir de la idea que la construcción urbana-metropolitana reciente es el fruto de procesos en tres dimensiones interconectadas: económica, socioresidencial y ecológica (Soja, 2014; Harvey, 2016). El cruce de estos procesos y su plasmación espacial ha ido generando modelos abiertos y evolutivos de ciudades (Cuadro 1).

CUADRO 1. TIPOS DE CIUDADES Y METRÓPOLIS. DINÁMICA EVOLUTIVA EN MÚLTIPLES DIMENSIONES

\begin{tabular}{lccc}
\hline & Régimen productivo & Estructura Socioresidencial & Modelo ambiental \\
\hline $\begin{array}{l}\text { Ciudad industrial } \\
\text { Metrópolis monocéntricas }\end{array}$ & Fordista & $\begin{array}{c}\text { Sociedad de clases } \\
\text { Urbanismo intensivo }\end{array}$ & $\begin{array}{c}\text { Cambio climático } \\
\text { y contaminación } \\
\text { atmosférica }\end{array}$ \\
\hline $\begin{array}{l}\text { Ciudad postindustrial } \\
\text { Metrópolis policéntricas }\end{array}$ & Flexible & $\begin{array}{c}\text { Sociedad dual } \\
\text { Urbanismo difuso }\end{array}$ & \\
\hline $\begin{array}{l}\text { Ciudad del conocimiento } \\
\text { Metrópolis en red }\end{array}$ & Creativo & $\begin{array}{c}\text { Sociedad compleja } \\
\text { Regeneración urbana }\end{array}$ & $\begin{array}{c}\text { Transición } \\
\text { ecológica }\end{array}$ \\
\hline
\end{tabular}

Fuente: Elaboración propia

En la dimensión económica, las décadas centrales del siglo xx consolidan procesos de producción y consumo de bienes estandarizados a escala masiva. La ciudad fordista consolida la especialización económica del espacio: implantaciones industriales intensivas en trabajo y desarrollo de redes de transporte. A finales del siglo XX se desencadena un importante cambio urbano. Se terciarizan las bases económicas de las metrópolis y ello genera un doble impacto territorial: los múltiples espacios del cierre industrial contrastan con la concentración de los tramos directivos en unos pocos distritos urbanos globales; y los espacios centrales de servicios financieros y tecnológicos contrastan con las periferias que alojan el terciario de escaso valor añadido. Emergen metrópolis con fuertes jerarquías y dualidades económicas en el territorio ${ }^{1}$. Durante las últimas décadas, ya en pleno siglo XXI, se desarrolla un nuevo giro económico-urbano con tres componentes clave. La creación de valor se desplaza al conocimiento y la reactivación industrial se produce bajo condiciones de innovación tecnológica; la actividad digital irrumpe con fuerza y las plataformas basadas en internet se insertan en la economía de las ciudades; finalmente, el capital financiero se activa hacia inversiones urbanas y tiende a craer lógicas de burbuja inmobiliaria. Estos cambios, en el plano territorial, producen un juego complejo de oportunidades y riesgos sobre la configuración metropolitana. Por una parte, el potencial de diluir jerarquías y segmentaciones espaciales hacia metrópolis más reticulares y sostenibles; por otra, la amenaza de los procesos de gentrificación económica y comercial.

En la dimensión socioresidencial, las décadas centrales del siglo XX, vienen marcadas por la presencia urbana masiva del trabajo asalariado, con la clase social como eje central de estratificación (Atkinson, 2016); así como por la producción fordista de bloques de vivienda en espacios residenciales de alta densidad y lógica suburbial-metropolizadora. A finales del siglo xx se despliegan dos cambios relevantes. En la vertiente laboral el mercado se polariza entre los nuevos sectores cualificados y el trabajo terciario precarizado con escasa articulación colectiva; y en el vector residencial se produce la ciudad extensiva como espacio urbano y simbólico de las nuevas clases profesionales urbanas, con menor densidad y mixticidad ${ }^{2}$. La etapa actual vuelve a presentarse como un juego de fuerzas en tensión. Por una parte, el incremento sin precedentes de la complejidad social urbana (orígenes, hogares, edades...) emerge como oportunidad hacia espacios con nuevas morfologías diveras y compactas, hacia entornos creativos cruzados por lógicas de reconocimiento; por otra parte los impactos sociales de la financiarización urbana producen expulsiones y sustitución funcional y poblacional (Sassen, 2014).

En Europa central -Lombardía, Piamonte, Baviera, Baden-Wurtemberg, Austria, Rhone-Alpes- la crisis del fordismo urbano dio lugar a tejidos productivos en red, cadenas de pymes interdependientes, dinámicas intercooperativas... Ello produjo regiones urbanas menos jerarquizadas y segmentadas (TRULLÉN, 2015).

2 Algunas metrópolis han mostrado la posibilidad de transitar de la ciudad industrial a la postindustrial sin dualización social. El cruce de regímenes de bienestar en fase expansiva con políticas urbanas de cohesión puede hallarse en la raíz. El caso de Barcelona aparece como uno de los referentes (PORCEL, 2016). 
En la dimensión ecológica, durante las décadas centrales del siglo pasado se produjo un modelo de intensos impactos ambientales: economías urbanas con alta dependencia de energías fósiles, y expansión de la movilidad motorizada en vehículos privados. Desde finales del siglo XX ese esquema se recrudece, y no es hasta una fase muy reciente que empiezan a ponerse en marcha estrategias para revertirlo. El crecimiento de emisiones provoca una realidad de cambio y alerta climática, con las metrópolis como agentes clave del calentamiento global; el uso masivo del coche se halla en la raíz de la contaminación del aire, principal determinante ambiental de la salud; y se desencadena finalmente un proceso de consumo extensivo de espacio: entre 1996 y 2016, la población urbana crece un 25\%, pero el territorio urbanizado se expande un $40 \%$. Tenemos hoy metrópolis con riesgos ecológicos socialmente producidos por la desprotección del clima, la degradación del aire y la depredación del espacio.

En síntesis, la ciudad fordista y de clases que se dualizó y lo plasmó en procesos de urbanismo difuso, la que dio lugar a ámbitos metropolitanos policéntricos y economías terciarizadas, cruza hoy un cambio de época urbano hacia metrópolis conectadas en red, hacia espacios donde se expresan todas las complejidades: vulnerables a la financiarización pero enormemente creativas; cargadas de tantas fragilidades sociales como energías comunitarias; responsables del cambio climático y referentes a la vez de transiciones ecológicas avanzadas (Nel.lo y Mele, 2016; Pascual, 2016).

¿Cómo dotar a esta realidad desbordante de una nueva agenda urbana que haga posible el ejercicio cotidiano del derecho a la ciudad? ¿Qué esquemas de gobernanza pueden producir las capacidades colectivas y las políticas públicas necesarias?.

\section{LO COMÚN Y LA PROXIMIDAD: CAPACIDADES COLECTIVAS FRENTE A JERARQUÍAS, CIUDADES FRENTE A ESTADOS?}

En el marco de la nueva era urbana, emerge con fuerza un renovado interés -tanto social como académico- en torno a la idea de lo común: alrededor de formas de gobierno y gestión de espacios, bienes y procesos de transformación que tratan de ubicarse en parámetros ajenos a la dicotomía clásica público/ institucional versus privado/mercantil (Bollier, 2014). Lo común sin embargo tiene sólidas raices en el campo teórico. Polanyi (2016) planteó como el avance del paradigma binario mercado-estado había provocado la erosión histórica de las bases cooperativas de la sociedad. Bases que, según demostró Ostrom (2012), incorporan elementos sólidos para una gobernanza comunitaria de los recursos compartidos. De forma más reciente, la teoría de los (bienes) comunes ha sumado otras dos aportaciones relevantes: en el terreno de los valores, Rosanvallon (2012) sitúa la comunalidad, es decir, la activación cotidiana de vínculos solidarios como lógica complementaria a las políticas de reconocimiento de las diferencias; en el terreno de las prácticas, Hardt y Negri (2009) ponen énfasis en lo común como verbo, en el commoning en tanto que construcción sostenida de capacidades constituyentes de autogobierno social transformador.

¿Cuáles son hoy los motivos del resurgimiento de lo común?. Se observa por una parte que las dinámicas de relación social estrictamente mercantiles no sólo no protegen a los que las practican, sino que generan altos niveles de desigualdad y segregación. Las necesidades de protección y cohesión, por otra parte, fueron hallando a lo largo del siglo XX respuestas diversas -New Deal en EEUU, regímenes de bienestar en Europa...- pero todas ellas de matriz estatalista y jerárquica. La pregunta hoy es si las inquietudes y malestares ciudadanos derivados de las aceleradas dinámicas de globalización y transición digital pueden encontrar de nuevo respuestas en modelos de protección a escala nacional y lógica vertical; o deben explorar alternativas vinculadas a la construcción del común en ámbitos de proximidad. Lo estatal en términos clásicos no aparece ya con capacidad suficiente de dar respuestas emancipadoras y protectoras ante las injusticias e inseguridades que plantean tanto la mercantilización global como las disrupciones generadas por el cambio digital en los itinerarios vitales de la humanidad.

Lo común resuena como un espacio de protección nacido en la cotidianidad de las personas, desde sus necesidades e incertidumbres, buscando lógicas de autogobierno y autogestión para crear bases materiales y emocionales de existencia humana. Laval y Dardot (2015) sintetizan la política del común como la articulación de democracia activa, generación cooperativa de valor, y apropiación comunitaria de servicios públicos. Más allá de las estrategias clásicas de los movimientos sociales frente a los poderes públicos, pivotando en el eje que va de la delegación/incidencia a la oposición/resistencia, la construcción del común implica erigir un espacio de creación/disidencia, de autonomía creativa, orientada a satisfacer necesidades y autotutelar derechos. Ejemplos de todo ello los tenemos en la constitución de espacios como «Som Energia» 
GAPP. Nueva Época - N. 20, noviembre 2018 - ISSN: 1989-8991 - DOI: 10.24965/gapp.v0i20.10491 - [Págs. 14-28] Número monográfico - Gobernanza y políticas de desarrollo urbano: teoría y práctica

El nuevo municipalismo: derecho a la ciudad y comunes urbanos Ismael Blanco / Ricard Gomà / Joan Subirats

(cooperativa de consumo de energía verde), Obra Social de la PAH (comunes urbanos), Wikipedia (común del conocimiento) o GuifiNet (común de acceso a internet). Estas prácticas y otras muchas ilustran cómo la perspectiva de lo común toma fuerza: en tanto que alternativa a una lógica de financiarización que precariza y la vida; y en tanto que alternativa a una lógica clásica de protección institucional top-down (Rendueles y Subirats, 2016).

CUADRO 2. MERCADOS, ESTADOS Y CIUDADES: ESCALAS TERRITORIALES Y LÓGICAS PREDOMINANTES

\begin{tabular}{lccc}
\hline & Eje apertura/cierre & Eje protección/vulnerabilidad & Lógicas predominantes \\
\hline Mercados globales & Apertura & Vulnerabilidad & Cosmopolitismo y precarización \\
\hline Fronteras estatales & Cierre & Protección & Pertenencia y exclusión \\
\hline Redes de ciudades & Apertura & Protección & Comunidad y diversidad \\
\hline
\end{tabular}

Fuente: Elaboración propia

Lo común no sólo se orienta a la exploración de alternativas a lo estatal clásico; conduce también a alterar la escala territorial: del ámbito nacional a la realidad de las ciudades. Cada vez más el reto consistirá en saber mantener nuestras sociedades abiertas (frente a reacciones de cierre xenófobo) y al mismo tiempo protegidas (frente a lógicas globales vulnerabilizadoras). Resulta clave trabajar en algo tan aparentemente contradictorio como articular sentido de pertenencia y capacidad de protección, con voluntad de acogida y reconocimiento pleno de la diversidad. El cuadro 2 ofrece una propuesta de articulación conceptual en este sentido. Las escalas territoriales (global, nacional-estatal y urbana) se definen por su cruce con el doble eje apertura/cierre y protección/vulnerabilidad. $Y$ es ahí donde las ciudades emergen como espacios que permiten el ensamblaje de la lógica de construcción comunitaria con el tejido de la heterogeneidad, del respeto a las diferencias. En este escenario de coordenadas, las metrópolis ofecen un potencial de respuesta que no está al alcance de los estados, demasiado encerrados en sus rigideces y rutinas. La proximidad es la gran palanca de transformación sobre la que tratar de proteger sin cerrar; el ámbito sobre el que tratar de construir comunes (Olmedo y Endara, 2017).

Pero la realidad presenta aún límites en ese doble sentido. Las ciudades, sus gobiernos locales, se encuentran presionadas por entramados de subordinación: no se sitúan en la centralidad del reparto de recursos públicos de poder; no se sitúan en el núcleo de los regímenes de bienestar y transición ecológica. Los estados pesan demasiado. Es por ello que cabe plantear un triple reto hacia un nuevo esquema de gobernanza multinivel: a) el reto del empoderamiento de las ciudades; $b$ ) el reto de las interdependencias horizontales; c) el reto del scaling up de políticas y prácticas urbanas.

El empoderamiento implica aumentar de forma sustancial las capacidades institucionales y colectivas de gobierno en la esfera local (Subirats, 2016). Resulta necesario en cuestiones como la acogida de personas migrantes, la transición energética o el control público de alquileres, policy issues vinculadas a lo cotidiano donde resulta además probado el fracaso de su abordaje en el ámbito estatal (Barber, 2013). Es cierto que todo ello requiere gobernanza multinivel y entra aquí en juego el segundo reto: transitar de un esquema top-down, de subordinación de las ciudades a los niveles «superiores», a otro de tipo horizontal donde la escala no implique jerarquía. Se trata pues de articular una gobernanza entre iguales como nueva gramática política entre ciudades, regiones, estados e instituciones supranacionales. Significa en la práctica que las ciudades codecidan y cogobiernen, por ejemplo, la Nueva Agenda Urbana, el Acuerdo Climático de París, o la dimensión social de la UE (el nuevo social pillar). Finalmente, las prácticas urbanas y las políticas locales deberían afrontar el desafío de su scaling up: su transferencia por medio de redes de municipalismo internacional y de procesos de policy learning multinivel. Si hace unas décadas, en una realidad menos compleja se trataba de «pensar global y actuar local»; ahora, en un mundo más complejo e interconectado se trata también de «pensar local y actuar global» (internet y el espacio digital lo hacen mucho más factible).

Cabe afirmar que en los tres ejes se hallan hoy ejemplos que dibujan trayectorias de cambio y perfilan futuros posibles y diferentes. El cuadro 3 recoge algunos de ellos. Son en algunos casos redes de aparición reciente, o bien redes aún incipientes en cuanto a su capacidad de incidencia para acercarse a los modelos deseados: 
a) Las Ciudades de Acogida emergen, frente al fracaso de la Unión y los estados, como propuestas de empoderamiento local para hacer frente a la crisis de los refugiados en Europa; mientras que el C-40 es la red global de metrópolis que lideran las políticas locales de protección climática bajo el paraguas del Acuerdo de París. Em ambos casos se construyen capacidades de gobierno urbano sin precedentes, más allá de las atribuciones formales de competencias.

b) Eurocities y CGLU son quizás los dos intentos más avanzados de consolidar redes de protagonismo municipalista en sus respectivos escenarios de gobierno multinivel: presencia directa de las ciudades en las políticas de la Unión, y en la agenda urbana de Naciones Unidas, respectivamente.

c) Por último, las transition towns configuran un muy interesante movimiento de ciudades europeas que han emprendido, cruzando aprendizajes, la ruta de la transición ecológica, mientras que las ciudades educadoras representan uno de los primeros moviminetos globales de innovación política de raíz municipal.

Hay en todo ello mucho camino a recorrer, pero empieza ya a esbozar una geografia europea e internacional de ciudades con vocación de hacer frente a los retos de la era urbana, desde agendas políticas de acción potentes, interconectadas y no subordinadas.

CUADRO 3. EMPODERAMIENTO URBANO, GOBERNANZA HORIZONTAL Y TRANSFERENCIA POLÍTICA

\begin{tabular}{lccc}
\hline & $\begin{array}{c}\text { Redes de } \\
\text { empoderamiento local }\end{array}$ & $\begin{array}{c}\text { Redes de } \\
\text { gobernanza multinivel }\end{array}$ & $\begin{array}{c}\text { Redes de } \\
\text { transferencia política }\end{array}$ \\
\hline Ámbito Europeo & Ciudades de Acogida & Eurocities & Transition towns \\
\hline Ámbito global & C-40 & CGLU & Ciudades educadoras \\
\hline
\end{tabular}

Fuente: Elaboración propia

\section{GOBIERNO LOCAL Y ACCIÓN COLECTIVA URBANA EN ESPAÑA: HACIA UN ESCENARIO DE NUEVO MUNICIPALISMO}

Una vez perfilado el marco general de la nueva era urbana, las oportunidades y límites en torno al binomio emergente común/proximidad, y los retos de empoderamiento de las ciudades en redes de gobernanza horizontal, se hace ahora necesario girar la perspectiva hacia nuestro entorno; hacia la ya dilatada y compleja evolución de la esfera local democrática en España (Brugué y Gomà, 1998; Canal, 2013).

\subsection{La trayectoria del gobierno local: tres décadas de cambios (1979-2011)}

El cuadro 4 presenta en síntesis la evolución del gobierno local en España. Durante los años 80, las lógicas movilizadoras de la transición dan paso a un esquema representativo y partidizado. Se aprueban las primeras normas de participación y descentralización, que toman el relevo a procesos muy poco formalizados de diálogo y acuerdo con el movimiento vecinal. En la década de los 90 avanza la lógica eficientista y se repliega la ciudadana: se impulsan relaciones de tipo individualizador, en perjuicio de la activación comunitaria. Aparecen sin embargo nuevas redes vinculadas al ciclo social altermundialista y al fortalecimiento de la conciencia ambiental y de defensa del territorio. En el escenario de los años 2000 se inicia el proceso de diversificación del entramado de actores políticos, con la presencia de un número creciente de candidaturas ciudadanas (Ubasart, 2012). Se intensifica la gobernanza relacional, con más procesos de concertación, y presencia de lo local en redes multinivel. Las estructuras tradicionales de participación muestran síntomas de agotamiento, pero un tejido social cada vez más renovado plantea exigencias de apliación democrática real. A partir de 2010, la crisis, la austeridad y el 15M desvertebran el municipalismo de la década anterior. Todo se expresa en las ciudades y en entornos de cotidianidad. El pinchazo de la burbuja inmobiliaria deja un rastro de gobiernos locales frágiles; deja sobre todo una geografía de emergencia habitacional y de nuevas fracturas. Muchos ayuntamientos se convierten en la última trinchera de políticas sociales que afrontan la cobertura cotidiana de necesidades básicas. 
CUADRO 4. DINÁMICA EVOLUTIVA DEL MUNICIPALISMO EN ESPAÑA (1979-2011)

\begin{tabular}{|c|c|c|c|}
\hline & AÑOS 80 & AÑOS 90 & $2000-2010$ \\
\hline & $\begin{array}{l}\text { Del municipalismo } \\
\text { participativo } \\
\text { al profesional-burocrático }\end{array}$ & $\begin{array}{l}\text { El municipalismo } \\
\text { emprendedor } \\
\text { y gerencial }\end{array}$ & $\begin{array}{l}\text { El municipalismo } \\
\text { constructor } \\
\text { y la gobernanza en red }\end{array}$ \\
\hline $\begin{array}{l}\text { Modelos } \\
\text { Políticos }\end{array}$ & $\begin{array}{l}\text { Constitución de un modelo } \\
\text { demo-representativo, } \\
\text { partidizado }\end{array}$ & $\begin{array}{l}\text { Consolidación modelo } \\
\text { partitocrático } \\
\text { Recambio generacional } \\
\text { en liderazgos }\end{array}$ & $\begin{array}{l}\text { Coexistencia del modelo } \\
\text { de partidos con nuevas } \\
\text { candidaturas ciudadanas }\end{array}$ \\
\hline $\begin{array}{l}\text { Agendas } \\
\text { de actuación }\end{array}$ & $\begin{array}{l}\text { De la mejora de barrios a } \\
\text { la agenda tridimensional: } \\
\text { servicios personales, } \\
\text { territorio y promoción } \\
\text { económica }\end{array}$ & $\begin{array}{l}\text { Modelos de ciudad y } \\
\text { planeamiento estratégico. } \\
\text { Centralidad de la } \\
\text { agenda del crecimiento } \\
\text { postindustrial }\end{array}$ & $\begin{array}{l}\text { Políticas urbanas expansivas } \\
\text { (burbuja immobiliaria). } \\
\text { Regeneración de barrios }\end{array}$ \\
\hline $\begin{array}{l}\text { Modelos } \\
\text { de gestión }\end{array}$ & $\begin{array}{l}\text { Burocrattzación } \\
\text { y profesionalismo }\end{array}$ & $\begin{array}{l}\text { Nueva gestión pública } \\
\text { (NGP): Gerencialismo } \\
\text { y externalizaciones }\end{array}$ & $\begin{array}{l}\text { Profundización NGP. Concertación } \\
\text { público-privada. Trabajo en red }\end{array}$ \\
\hline $\begin{array}{l}\text { Estructuras de } \\
\text { participación }\end{array}$ & $\begin{array}{l}\text { Del diálogo con el movimiento } \\
\text { vecinal a la formalización } \\
\text { de espacios participativos }\end{array}$ & $\begin{array}{l}\text { Consolidación de } \\
\text { espacios formales. } \\
\text { Surgimiento procesos/ } \\
\text { instrumentos de } \\
\text { innovación democrática }\end{array}$ & $\begin{array}{l}\text { Crisis estructura formales. } \\
\text { Planes directores de participación. } \\
\text { Nuevos escenarios de gobernanza }\end{array}$ \\
\hline $\begin{array}{l}\text { Ciudadania } \\
\text { y tejido social }\end{array}$ & $\begin{array}{l}\text { Crisis del movimiento vecinal } \\
\text { clásico y surgimiento } \\
\text { de un nuevo tejido de } \\
\text { entidades }\end{array}$ & $\begin{array}{l}\text { Nuevos activismos } \\
\text { urbanos y ambientales. } \\
\text { Vínculos con ciclo } \\
\text { alterglobalizador }\end{array}$ & $\begin{array}{l}\text { Tejido asociativo diversificado. } \\
\text { Surgimiento resistencias a } \\
\text { especulación immobiliaria y urbana }\end{array}$ \\
\hline
\end{tabular}

Fuente: Elaboración pròpia (a partir de Blanco, Gomà, 2016)

\subsection{Dinámicas de movilización urbana (2011-2015)}

Emerge en este tiempo un mosaico movilizador: desde la PAH (plataforma antideshaucios) a las asambleas sociales inscritas en la dinámica del 15M; desde las mareas en defensa de los servicios públicos a las huelgas generales contra la reformas laborales. Y surge también una cartografía de prácticas de innovación social: desde la economía solidaria a las redes de intercambio; desde las cooperativas de consumo agroecológico a la gestión comunitaria de vacios urbanos. Adoptando el prisma de la movilización, va cristalizando una geografía de acción colectiva que podemos esquematizar en el cuadro 5.

- el sí se puede contra la emergencia habitacional y la pobreza energética,

- el derecho a la ciudad frente a la especulación y la mercantilización de espacios,

- la lucha laboral de las mujeres en marcos precarizados de economía urbana,

- la acción en favor de la acogida y la plena ciudadanía de refugiados y migrantes,

- las soberanías de proximidad (agua pública y sistemas alimentarios alternativos).

CUADRO 5. ORGANIZACIONES, REDES, TEMÁTICAS Y MOVIMIENTOS DE REFERENCIA

\begin{tabular}{|c|c|c|}
\hline $\begin{array}{l}\text { Dinámica de movilización } \\
\text { (organización/red) }\end{array}$ & $\begin{array}{l}\text { Temática } \\
\text { (espacio de gobernanza) }\end{array}$ & $\begin{array}{l}\text { Movimiento social } \\
\text { de referencia }\end{array}$ \\
\hline $\begin{array}{l}\text { - Plataforma afectados por la hipoteca } \\
\text { - Alianza contra pobreza energética }\end{array}$ & $\begin{array}{l}\text { Emergencia habitacional } \\
\text { Pobreza energética }\end{array}$ & $\begin{array}{l}\text { Urbano/vecinal } \\
\text { Derechos sociales }\end{array}$ \\
\hline $\begin{array}{l}\text { - Sindicato de inquilinos } \\
\text { - Redes de autogestión urbana }\end{array}$ & $\begin{array}{l}\text { Derecho a la vivienda } \\
\text { Derecho a la ciudad }\end{array}$ & $\begin{array}{l}\text { Urbano/Vecinal } \\
\text { Autogestión }\end{array}$ \\
\hline
\end{tabular}




\begin{tabular}{lll}
\hline - Sindihogar & Precariedad laboral, género & Sindical \\
- Las kellys & y cuidados & Feminista \\
\hline - Queremos acoger & Acogida y ciudadanía & Solidaridad Internacional \\
\hline - Agua es vida & & Antiracismo \\
- Redes de soberanía alimentaria & $\begin{array}{l}\text { Soberanías de proximidad: agua y y } \\
\text { sistema alimentario }\end{array}$ & Ecologismo \\
\hline
\end{tabular}

Fuente: Elaboración propia

Se trata de cinco dinámicas que presentan algunas características de enorme interés. Son redes conectadas a problemas de escala supralocal, pero cuya expresión se da en el ámbito de lo urbano, «de las ciudades como expresión de contradicciones y conflictos que dan forma a la cotidianidad» (Lefebvre, 1972). Cada dinámica se enmarca en un movimiento social más amplio, pero forja una expresión concreta cuya esfera política de referencia es sobre todo municipal. Son formatos innovadores de acción colectiva: en su modelo organizativo (de orientación comunitaria); en su repertorio de acción (más disruptivo que convencional); en su narrativa (producen relatos con fuerte capacidad de penetración social). Son, finalmente, redes con clara voluntad de impacto en las agendas municipales.

\subsection{El escenario local post-2015: hacia un nuevo municipalismo}

Todas estas realidades se hallan en la genealogía de los nuevos actores que irrumpen en las elecciones locales de 2015. Se planteó un reto doble: transitar de la fragmentación de prácticas y actores a la confluencia; y de la esfera social a la arena política. Se fueron configurando nuevos sujetos municipalistas, resultantes de procesos de suma entre culturas de acción emergentes y preexistentes; entre la ciudadanía y espacios políticos ya organizados. Los nuevos actores emergen con fuerza. Las ciudades otorgan a las nuevas candidaturas las primeras mayorías socioelectorales. Las candidaturas alternativas, desde mayo de 2015, lideran el gobierno de 4 de las 5 mayores ciudades (Madrid, Barcelona, Valencia y Zaragoza); consiguen también ganar o formar gobierno en municipios tan relevantes como Santiago, A Coruña, El Ferrol, Pamplona, Cádiz, Badalona y Sadadell.

Es un nuevo escenario sustancialmente diferente a todos los precedentes, pero que nace también con dinámicas en tensión: a) La asunción de cultura de gobierno puede mermar la capacidad disruptiva de los nuevos actores, pero también generar nuevas lógicas de relación entre lo institucional y lo social, desde el reconocimiento mutuo, la alianza público-ciudadana y los procesos de commoning (Stavrides, 2016). b) El contexto de austeridad puede ser procesado por el mundo local desde la resignación, pero también desde la oportunidad de construcción de alternativas: nuevas políticas de proximidad, procesos de apropiación comunitaria de servicios y espacios urbanos, una gestión más democrática y ciudadana (Harvey, 2012). c) Los impactos de la crisis generan sobre las personas miedos y vivencias del sufrimiento en ámbitos privados y domésticos, pero también nuevas dinámicas de innovación social, procesos de empoderamiento y prácticas de tipo cooperativo (Barranco, González y Llobet, 2016; Parcerisa, 2014). d) La expansión de internet reproduce desigualdades urbanas en términos de fractura digital (Dupuy, 2007), pero abre opciones inéditas de construcción de conocimientos compartidos, hace posible ciudades de código abierto como dimensión clave del nuevo municipalismo (Blanco y Gomà, 2016).

En síntesis, hemos considerado la trayectoria, el contexto y las bases del nuevo escenario. Una trayectoria de municipalismo cambiante que deja impactos y sufre vuelcos; un contexto de crisis y cambio de época que convoca a respuestas creativas y transformadoras; y un escenario de nuevos actores sociales y políticos urbanos que irrumpen en los gobiernos locales y enfrentan dinámicas en tensión. Todo ello establece las bases para analizar los contenidos del nuevo modelo: la agenda de políticas urbanas y los procesos de producción de estas políticas (Soja, 2014).

\section{LA NUEVA AGENDA URBANA COMO CONSTRUCCIÓN DEL DERECHO A LA CIUDAD}

¿Estamos ante una nueva agenda municipalista comprometida con el derecho a la ciudad? ¿Estamos ante formas de coproducción de la ciudad articuladoras de la política del común? En el terreno sustantivo, el nuevo municipalismo despliega una triple dimensión de políticas: ecología urbana, economías ciudadanas y 
bienestar de proximidad (cuadro 6), una agenda orientada a forjar el derecho a la ciudad. (Borja, Carrión y Corti, 2016). Cada uno de esos vértices temáticos interacciona con los dos restantes, dando lugar a los tres ejes vertebradores de la agenda: el desarrollo sostenible como espacio de encuentro entre actividades productivas y entornos ambientales; la prosperidad compartida como lógica de diálogo entre economías y cohesión social; y la habitabilidad convivencial como propuesta de intersección entre la ecología y el bienestar cotidiano.

\section{Ecología urbana}

La plasmación territorial del modelo económico predominante ha dejado un legado de ciudades insostenibles y con graves problemas de injusticia espacial. Frente a esta doble realidad, el nuevo municipalismo asume el reto de construir la agenda de la habitabilidad sobre la base de hibridar las lógicas ambiental y urbana. Un nuevo urbanismo democrático y de género para la recuperación de calles y plazas; un nuevo urbanismo del bien común para hacer frente a la gentrificación, garantizar viviendas asequibles y preservar el derecho al barrio. Y un nuevo ecologismo que haga posible la vida: la protección del clima (transición energética) y la calidad del aire (movilidad sostenible); la soberanía alimentaria y la gestión pública del agua.

\section{Economías ciudadanas}

En el esquema económico predominante a escala global, las ciudades operan como plataformas de aterrizaje del capital financiero, como espacios desencadenantes de lógicas especulativas de burbuja (inmobiliaria, turística, lúdica, comercial...). Frente a ello, el nuevo municipalismo erige la apuesta por tejidos industriales y comerciales articulados a las comunidades, conectados a la resolución de necesidades y generadores de sociabilidad. Redes y ecosistemas cooperativos, cadenas de creación y apropiación compartida de valor, economías verdes y circulares. Un modelo que incorpora garantías de empleo y salario digno. El reto pasa por tanto por construir economías urbanas del bien común, innovadoras y conectadas a la investigación pública, sólidamente tramadas en la proximidad. Y sobre esas bases, abiertas a la economía global productiva, creativa y del conocimiento.

\section{CUADRO 6. NUEVA AGENDA URBANA, DERECHO A LA CIUDAD Y GESTIÓN DEL COMÚN}

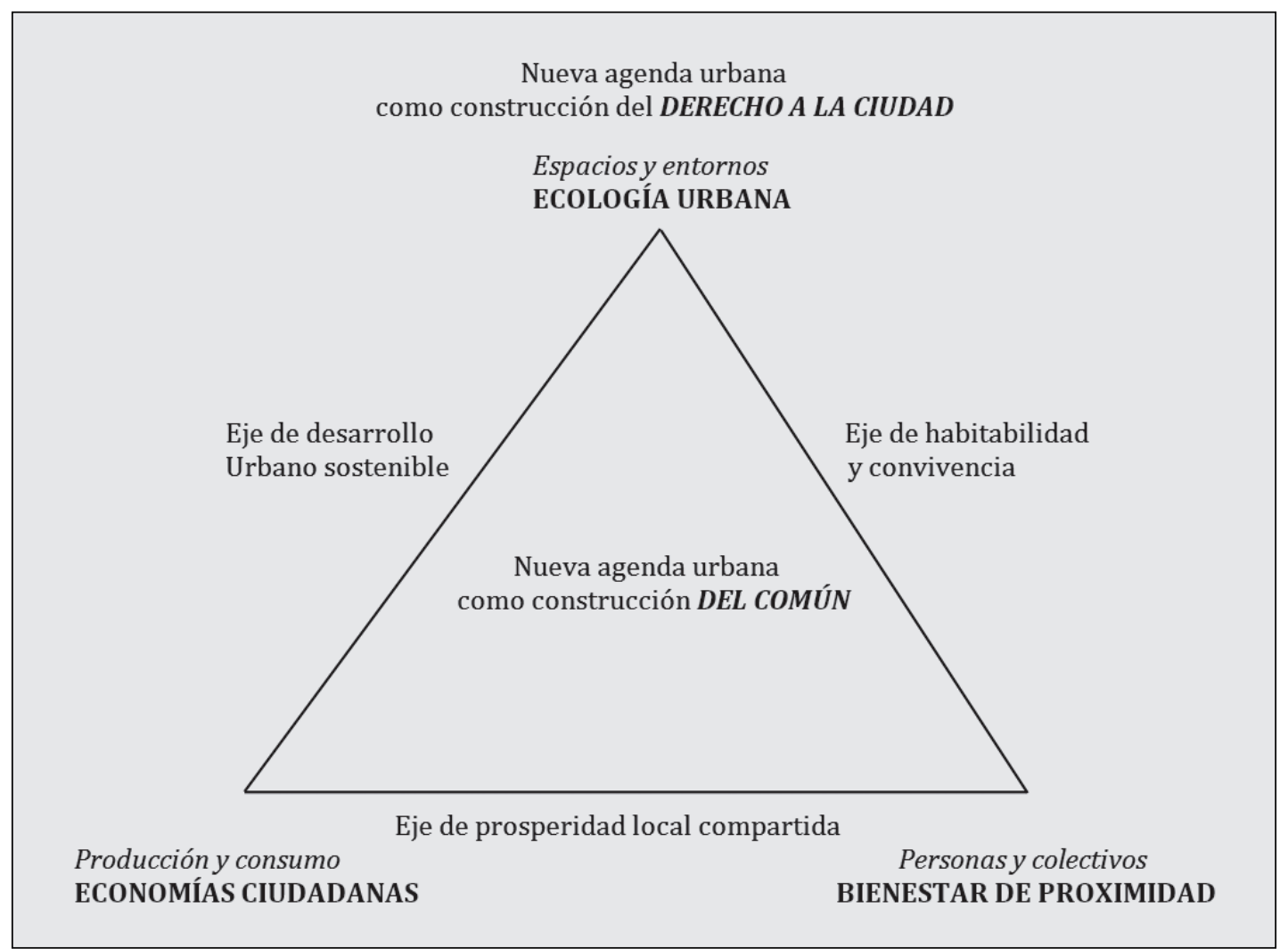

Fuente: Elaboración propia 


\section{Bienestar de proximidad}

La cartografía urbana de las injusticias sociales se expresa en tres dimensiones: persisten desigualdades clásicas de renta, educativas y de salud; emergen en los barrios nuevas vulnerabilidades derivadas de cambios en la estructura socioeconómica (procesos de acogida frágiles, soledad y exclusión relacional, precariedad vital y laboral...); y cristalizan los impactos de la crisis gestionada bajo políticas de austeridad (emergencia habitacional, pobreza energética, segregación urbana...). En este marco, el nuevo municipalismo se convierte en el espacio básico de reconstrucción de derechos sociales, desde una exigencia de innovación, más allá de los parámetros clásicos del estado de bienestar. Se trata de forjar una red potente de servicios de proximidad, explorar el avance hacia rentas garantizadas (Van Parijs y Vanderborght 2017), impulsar una distribución paritaria de los cuidados, tejer políticas de inclusión social urbana y articular vías de acogida y convivencia intercultural. Se trata, en síntesis, de generar una fuerte dimensión urbana de bienestar y conseguir ubicarla en el centro del modelo social; retornar a las ciudades los mecanismos de la solidaridad colectiva que el siglo xx reservó a los estados-nación.

\section{LA NUEVA AGENDA URBANA COMO CONSTRUCCIÓN DEL COMÚN}

No se trata únicamente de formular nuevas políticas orientadas al derecho a la ciudad; a hacer efectiva la dimensión urbana de la justicia social, económica y ambiental. Se trata también de producir el derecho a la ciudad por medio de nuevos procesos alejados de lógicas jerárquicas y del monopolio burocrático; nuevos procesos superadores de las viejas formas de institucionalidad que reservan a la ciudadanía un papel pasivo de receptor de servicios. La nueva agenda urbana adquiere pleno sentido en la mediada que articula espacios donde forjar implicaciones cotidianas, creación de redes de fraternidad.

Pueden considerarse cinco estrategias de gestión urbana como construcción del común:

1. Territorializar la gobernanza. Aparece como fundamental acercar las políticas urbanas a la escala de barrio. La complejidad social hace necesaria una arquitectura más espacial de la agenda municipal. Para construir autonomía personal y bien común en una sociedad líquida y cruzada por riesgos múltiples es preciso generar un modelo urbano de fuerte proximidad, ligado a la cotidianidad.

2. Coproducir políticas urbanas. Coproducir el derecho a la ciudad implica articular redes de acción, forjar procesos de código abierto como exigencia ética y como valor operativo: sumar conocimientos socialmente distribuidos. Coproducir políticas urbanas implica la participación del tejido comunitario en sus procesos de diseño e implementación; implica el protagonismo de las personas en tanto que sujetos activos en el ejercicio de la ciudadanía.

3. Impulsar la acción comunitaria. Territorializar, coproducir... y empoderar también a las comunidades, fortalecer su autogobierno para desplegar capacidades colectivas de resolución de problemas, para autogestionar respuestas, para hacer tangible el derecho a la ciudad desde la base. La acción comunitaria como herramienta de producción urbana desde valores democráticos y desde el compromiso personal libre y consciente; como antídoto al individualismo neoliberal y al paternalismo institucional.

4. Abrir la gestión a la ciudadanía. Una agenda municipal enraizada en la lógica del común implica incorporar una apuesta de gestión de servicios y espacios urbanos conectada a la implicación vecinal. Los equipamientos sociales, culturales, educativos, de salud... así como muchos espacios públicos son los referentes tangibles en el ejercicio cotidiano de la ciudadanía. Configuran la geografía física del bienestar. Deberían configurar también su geografía humana, colectiva y emocional; superar la lógica tradicional de marcos físicos de prestación de servicios, y convertirse en verdaderos bienes comunes, lugares de apropiación colectiva desde valores democráticos.

5. Apoyar la innovación social. La iniciativa que viene de abajo sin impulso ni mediación institucional, es un valor a reconocer en una agenda urbana creadora del común. Existe un tejido comunitario que vehicula prácticas de solidaridad y reciprocidad. La crisis y el impacto de los recortes ha estimulado experiencias de innovación social. No es la clásica participación de la protesta o la propuesta; es la implicación del hacer (y del ser): hacer (y ser) por ejemplo una escuela activa, un grupo de crianza compartida, una red de intercambios, una cooperativa de consumo agroecológico, un ateneo popular o un huerto comunitario. Toda una esfera urbana a poner en valor: desde su autonomía, desde marcos de apoyo anclados en valores de construcción plural de la ciudad (Subirats, García, 2015) 


\section{ARTICULAR DERECHO A LA CIUDAD Y COMUNES URBANOS}

Es el gran reto: interseccionar derecho a la ciudad con democracia del común como forma de producirlo. En esa articulación, las políticas urbanas promueven ciudadanía activa y empoderamiento; los servicios públicos se reconfiguran como bienes comunes de apropiación colectiva; y las prácticas sociales crean justicia de base y autogobierno comunitario. Ahí estaría la piedra angular del municipalismo del común: ubicar la esfera local como marco del proceso instituyente del cambio de época. Situar lo urbano como motor de reconstrucción de la lógica comunitaria de la democracia, de la lógica colectiva de los derechos; como impulsor de alternativas más que de resistencias. El municipalismo del común genera una esfera pública compartida: con presencia institucioonal y comunitaria, con alianzas y procesos de coproducción. Implica conjugar una dimensión sustantiva de justicia urbana con una dimensión operativa de democracia abierta. Un campo de intersecciones donde la agenda urbana adquiere pulsión comunitaria activadora de ciudadana; donde las prácticas sociales adquieren fuerza universalista constructora de derechos; donde todo ello queda entrelazado.

¿Podemos analizarlo a través de experiencias concretas? En el libro «El municipalisme del bé comú» (Blanco, Gomà 2016) planteamos un conjunto de casos ilustrativos, narrados por sus propios protagonistas. Los presentamos por medio de una matriz (cuadro 7) estructurada en cinco ejes clave de la agenda urbana: democracia abierta, economía cooperativa, derechos básicos, entornos sostenibles y vínculos solidarios. Cruzamos cada dimensión por una política urbana creadora de ciudadanía activa, y por una práctica ciudadana creadora de política democrática. Surge así un mosaico de iniciativas donde identificar los avances y los límites; los retos del nuevo municipalismo. Veamos como ejemplo ilustrativo el de la Obra Social de la PAH.

CUADRO 7. LA MATRIZ DEL MUNICIPALISMO DEL BIEN COMÚN

\begin{tabular}{l|l|l|l|}
\hline \multicolumn{2}{c}{$\begin{array}{c}\text { Políticas publicas } \\
\text { creadoras de ciudadanía activa }\end{array}$} \\
\cline { 1 - 1 } Democracia abierta & & \multicolumn{2}{c}{$\begin{array}{c}\text { Prácticas ciudadanas } \\
\text { creadoras de política democrática }\end{array}$} \\
\cline { 1 - 1 } Economía cooperativa & & \multicolumn{3}{|c|}{ Producción en común del derecho a la ciudad } \\
\cline { 1 - 1 } Derechos básicos & & \\
\hline Entornos sostenibles & & \\
\hline Vínculos solidarios & &
\end{tabular}

Fuente: Elaboración propia (a partir de Blanco, Gomà, 2016)

\subsection{La Plataforma de Afectados por la Hipoteca: coproducir comunes urbanos de vivienda}

En Cataluña y España, las políticas sociales de vivienda han sido inexistentes o no han llegado a desplegarse como una dimensión básica del estado de bienestar. La vivienda se ha situado bajo la lógica del mercado: una mercancia más que un derecho; un valor de cambio más que un valor de uso. Durante años asistimos en España a una combinación letal para el derecho a la vivienda. Por una parte una legislación hipotecaria y de arrendamientos urbanos hecha a medida de los bancos, abusiva y contraria al derecho europeo. Por otra parte un ciclo de crecimiento económico financiarizado y con predominio de prácticas especulativas: mercantilización de un derecho básico y dinámicas de burbuja. En este doble contexto, el derecho a la vivienda queda vulnerado. A partir del estallido de la burbuja, del rescate de los bancos con dinero público y de los recortes sociales, el drama de los deshaucios emerge como una realidad cotidiana.

En este marco de especulación y crisis, de debilidad persistente de la vivienda en la arena pública, el papel de la Plataforma de Afectados por la Hipoteca (PAH) ha llegado a ser fundamental. Lo ha sido por dar visibilidad a un problema oculto (construcción de agenda); por articular propuestas concretas; y por empoderar a personas y comunidades con el dolor previamente silenciado y privatizado: por convertirlas en protagonistas de la construcción del común. La PAH se constituye en Barcelona en febrero del 2009. Luego de 8 años de activismo, se han creado cerca de 250 PAH locales en toda España, con más de 1.500 
deshaucios paralizados. En abril de 2011 la PAH da un paso adelante cualitativo. Más allá del repertorio de acción colectiva clásico (movilización, presión, incidencia, tribunales...) comienza a explorar una vía con fuertes componentes de disidencia y autonomía, la Obra Social. Una estrategia de reapropiación ciudadana de viviendas vacías en manos de entidades financieras fruto de ejecuciones hipotecarias. Entre 2009 y 2017 , la Obra Social ha recuperado cerca de 50 bloques en más de 15 ciudades españolas, y por encima de 3.000 personas realojadas (Nel.lo, 2015).

\section{La Obra Social de la PAHC de Manresa: derecho a la vivienda, disidencia y producción del común}

Manresa es una ciudad de 70.000 habitantes de pasado manufacturero y epicentro urbano de la Cataluña central. A partir de 2010 el desempleo estructural y los impactos de la crisis, junto a la debilidad histórica de las políticas municipales de vivienda, provocan una situación de exclusión residencial, así como de fuertes dificultades en el pago de hipotecas y alquileres. Las políticas de austeridad y recortes dejan además a los servicios sociales con márgenes muy estrechos de respuesta paliativa a la emergencia habitacional. Junto a todo ello se desencadenan dos dinámicas urbanas. a) la degradación del parque inmobiliario del centro histórico, que provoca un proceso de salida de la población y un reguero de viviendas desocupadas. b) la apuesta durante los años de la burbuja por la expansión y la construcción masiva, que genera un estoc de pisos vacíos cuando estalla la crisis.

Este es el contexto en el que surge la PAHC (Plataforma de Afectados por la Hipoteca y el Capitalismo) de Manresa, cuya asamblea fundacional se celebra en diciembre de 2012. Entre junio de 2013 y agosto de 2014, la PAHC impulsa la ocupación («recuperación») de tres bloques de pisos vacíos. La primera reapropiación se da en el casco histórico, en una finca de una entidad bancaria, y se realojan cinco familias. La segunda tiene lugar en abril de 2014 en un bloque con 14 pisos vacíos propiedad de la SAREB (la sociedad estatal que gestiona los activos tóxicos bancarios vinculados al ladrillo). La tercera se produce en otro edificio de la SAREB con 18 viviendas desocupadas. Las tres acciones se orientan a hacer efectivo el derecho a la vivienda de personas y familias en riesgo de exclusión residencial, por procesos de ejecución hipotecaria o de deshaucios en pisos de alquiler. La evolución presenta escenarios diferentes. El bloque tercero sigue en situación de ocupación. En el bloque primero, la entidad financiera (Caixa Bank) interpuso una demanda judicial contra las familias ocupantes. Meses después, la presión vecinal llevó al banco a negociar. Fruto del proceso, la PAHC consigue el realojo de las familias en régimen de alquiler social, la cesión del edificio recuperado al parque de viviendas municipales y la rehabilitación de todos los pisos. También en el bloque segundo se consigue forzar una negociación que conduce a la SAREB a ceder el edificio al gobierno catalán, el cual llega a cuerdos de alquiler social con todas las familias, 46 personas con 21 menores. Más recientemente, a lo largo del año 2015, la PAHC impulsa la recuperación de los bloques cuarto y quinto, propiedad también del sector financiero, dando alojamiento a 54 persones y 19 menores. En el contexto de producción ciudadana de comunes urbanos, más allá de las viviendas reapropiadas, la PAHC pone en marcha, en octubre de 2016, una Escuela Popular en los bajos del bloque cuarto. Se concibe como un espacio de refuerzo educativo comunitario, gestionado por activistas, en el que participan 40 alumnos.

\section{Apuntes finales: los retos del municipalismo del común}

De la experiencia de la PAHC de Manresa, y a modo de apuntes finales, surgen preguntas y retos. ¿Es posible forjar el derecho a la vivienda en común desde parámetros de disidencia? ¿Es factible mantener y ampliar lógicas de autogestión y empoderamiento comunitario de forma sostenida, en un contexto de tanta fragilidad vital? ¿Deben ponerse los avances producidos en la reapropiación al servicio de una dinámica más audaz de interacción con el gobierno municipal?. El cuadro 8 ofrece pautas conceptuales para responder a estas preguntas. Plantea la triangulación entre delegar, denunciar y crear. es decir, entre la lógica clásica de incidencia institucional sobre la toma de decisiones, la también tradicional lógica de resistencia de los movimientos sociales urbanos (la PAH como ejemplo de espacio de resistencia ante los deshaucios), y la lógica emergente de disidencia, de autonomía creativa de comunes urbanos, donde podrían situarse las prácticas innovadoras antes consideradas de la Obra Social de la PAH. Podemos plantear finalmente estas cuestiones en clave de retos.

1. El reto de construir el derecho a la vivienda en común, superando las políticas vulnerables a intereses especulativos, sin caer más en la desresponsabilización ciudadana. Mantener y ampliar lógicas de 
autogestión y empoderamiento comunitario de forma sostenida, y poner de forma simultánea las conquistas producidas en la reapropiación de viviendas -con un alto grado de legitimidad ética y social- al servicio de una lógica complementaria de incidencia institucional.

2. El reto de mantener abiertas las vías de la autonomía y la disidencia, reforzando a la vez la estrategia para conseguir la implicación de los ayuntamientos en las políticas de vivienda pública de alquiler social por medio de la cesión de pisos vacíos. Se trataría, en síntesis, de alumbrar un nuevo municipalismo plenamente implicado en el derecho a la vivienda; y una acción colectiva urbana que mantiene acciones de autotutela del derecho, ya sea desde la autonomía (cooperativas) o desde la insumisión (reapropiaciones). Estaríamos ante la expresión del municipalismo del común: el derecho a la ciudad concretado en la agenda urbana de vivienda; y su producción y ejercicio desde parámetros colectivos, desde dinámicas de construcción del común.

\section{CUADRO 8. DE LA PAH A LA OBRA SOCIAL: DEL MOVIMIENTO URBANO A LA CONSTRUCCIÓN DEL COMÚN}

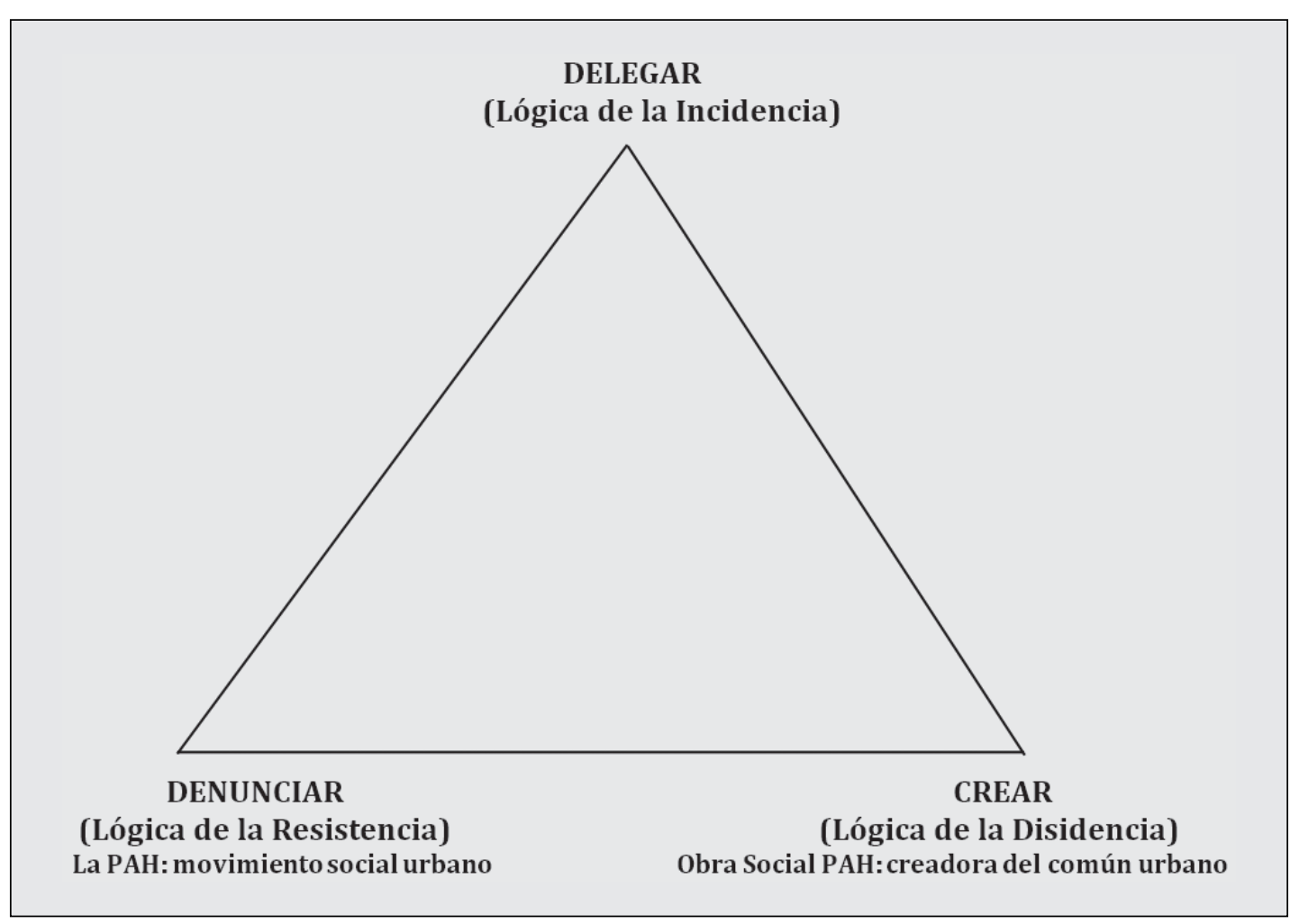

Fuente: Elaboración propia

Ambos retos señalan, finalmente, vías de avance en la agenda de investigación. Una agenda que presenta potencial de profundización en sus aspectos teóricos: la economía política de las metrópolis del siglo XXI, los modelos de gobernanza en red y el nuevo municipalismo del común. Y en sus vertientes de investigación aplicada: las nuevas políticas urbanas, y las prácticas de construcción de comunes en terrenos diversos: vivienda, educación, cultura de proximidad, organización de los cuidados, energía o economía digital.

\section{REFERENCIAS BIBLIOGRÁFICAS}

ATKINSON, A. (2016), Desigualdad ¿Qué podemos hacer? México: Fondo Cultura Económica.

BARBER, B. (2013), If mayors ruled the world: dysfunctional nations, rising cities, Yale: YUP.

BARRANCO, O., GONZÁLEZ, R. y LLOBET, M. (2016), "Del movimiento okupa a las PAH: cambios en las visiones e interpretaciones de la ocupación de viviendas”, Ponencia presentada en el XII Congreso Español de Sociología. Gijón: Federación española de Sociología. 
GAPP. Nueva Época - N. 20, noviembre 2018 - ISSN: 1989-8991 - DOI: 10.24965/gapp.v0i20.10491 - [Págs. 14-28] Número monográfico - Gobernanza y políticas de desarrollo urbano: teoría y práctica

El nuevo municipalismo: derecho a la ciudad y comunes urbanos Ismael Blanco / Ricard Gomà / Joan Subirats

BAUMAN, Z. (2003), Modernidad líquida. México: Fondo de Cultura Económica.

BECK, U. (1998), La sociedad del riesgo. Barcelona: Paidós.

BLANCO, I. y GOMÀ, R. (2016), El municipalisme del bé comú. Barcelona: Icària.

BOLLIER, D. (2014), Pensar desde los comunes. Madrid: Traficantes de Sueños.

BORJA, J., CARRIÓN, F. y CORTI, M. (2016), Ciudades para cambiar la vida. Quito: Flacso Ecuador.

CANAL, R. (2013), Ciudades y pueblos que puedan durar. Barcelona: Icària.

CAPEL, H. (1975), Capitalismo y morfología urbana en España. Libros de la Frontera.

CASTELLS, M. (2012), Redes de indignación y esperanza. Madrid: Alianza Editorial.

DUPUY, G. (2007), "La fractura digital hoy", en Revista de Ciencia, Tecnología y Sociedad, vol. 3, núm. 9, págs. 115133.

HARDT, M. y NEGRI, A. (2009), Common wealth. Madrid: Akal.

HARVEY, D. (2016), The ways of the world. Londres: Profile Books.

LAVAL, CH., y DARDOT, P. (2015), Común. Barcelona: Gedisa. DOI: https://doi.org/10.18504/p/2651-017-2018.

LEFEVBRE, H. (1972), La revolución urbana. Madrid: Alianza Editorial.

LEFEVBRE, H. (2017), El derecho a la ciudad. Madrid: Capitán Swing.

NEL.LO, O. (2015), La ciudad en movimiento. Madrid: Díaz Pons.

NEL.LO, O. y MELE, R. (2016), Cities in the 21st century. Londres: Routledge. DOI: https://doi. org/10.4324/9781315652221.

OLMEDO, P. y ENDARA, G. (2017), Alternativas urbanas y sujetos de transformación. Quito: FIS.

OSTROM, E. (2012), El gobierno de los bienes comunes. México: Fondo de Cultura económica.

PARCERISA, LL. (2014), “La PAH: un moviment social contrahegemònic?”, en Oxímora. Revista Internacional de Ética i Política, núm. 4, págs. 23-40.

PASCUAL, J. M. (2016), Las ciudades ante el cambio de era. Barcelona: Hacer.

POLANYI, K. (2016), La gran transformación. Barcelona: Editorial Virus.

PORCEL, S. (2016), Dinámicas de estructuración socioresidencial en la Barcelona metropolitana post-industrial: ¿Hacia una ciudad dual o cuarteada? Tesis Doctoral, UAB.

RENDUELES, C. y SUBIRATS, J. (2016), Los (bienes) comunes. Barcelona: Icària.

ROSANVALLON, P. (2012), La sociedad de los iguales. Barcelona: RBA.

SASSEN, S. (2014), Expulsions. Boston: Harvard University Press. DOI: https://doi.org/10.4159/9780674369818.

SOJA, E. (2014), En busca de la justicia espacial. València: Tirant Humanidades.

STRAVIDES, S. (2016), Common Space: The City as Commons. Chicago: U. Chicago Press Books.

SUBIRATS, J. (2016), El poder de lo próximo. Las virtudes del municipalismo. Madrid: Catarata.

SUBIRATS, J. y GARCÍA, A. (2015), Innovación social y políticas urbanas. Barcelona: Icària.

TRULLÉN, J. (2015), "G. Becattini and the Marshall's method”, en Investigaciones Regionales, núm. 32, págs. 43-60.

UBASART, G. (2012), Candidatures alternatives i populars a Catalunya. Barcelona: Icària.

VAN PARIJS, P. y VANDERBORGHT,Y. (2017), Basic Income. Boston: Harvard Univesity Press. 